\title{
Early and Midterm Results of 78 Ascending Aortic Aneurysm Cases after Surgical Treatment
}

\author{
Bilgehan $\mathrm{E}^{*}$ and Azman A \\ Department of Cardiovascular Surgery, Atatürk University Medical Faculty, Turkey \\ *Corresponding author: Bilgehan Erkut, Department of Cardiovascular Surgery, \\ Atatürk University Medical Faculty, Erzurum, Turkey, Tel: 0090533 7451006; Email: \\ bilgehanerkut@yahoo.com
}

Research Article

Volume 3 Issue 3

Received Date: April 08, 2019

Published Date: May 10, 2019

DOI: $10.23880 /$ mjccs-16000214

\section{Abstract}

Background: Ascending aortic aneurysms are lesions that should be surgically handled because of their life-threatening complications like rupture and dissection. The surgical treatments and the early-middle term results in patients with ascending aortic aneurysm were presented in this study.

Method: We retrospectively examined the records of 78 patients who underwent surgical treatment due to ascending aortic aneurysm between Aug 2006 and July 2018. The patients ranged in age from 24 to 77 years old (mean; 51.7 \pm 9.8 ). There were $54(69.2 \%)$ men and 24 (30.8\%) women. Fifty-eight (74.3\%) patients had Marfan's Syndrome. There was coronary arterial disease, mitral stenosis, aortic regurgitation, aortic stenosis, and aortic coarctation in 12, 3, 22, 7 and 2 patients, respectively. The emergency surgical treatment was required in 41 (52.5\%) patients.

Results: Only, 55 (70.5\%) patients had performed ascending aortic replacement. Bentall procedure was performed in the 14 patients, aortic valve replacement + ascending aortic graft replacement was made in 9 patients as separate replacement. In 14 patients totally circulatuar arrest was used. The operative mortality was occurred in $3(3.8 \%)$ patients with Bentall procedure and the early postoperative mortality occurred in $1(1,3 \%)$ patient with aortic coarctation.

Discussion: The enlargement process of the aortic diameter was should be close monitored and operated un-ruptured in ascending aortic aneurysms. Besides, Bentall procedure provids excellent results in terms of reduced complications and good cardiac functions in the patients with Marfan's Syndrome with the aortic root dilatation.

Keywords: Ascending Aorta; Aneurysm; Marfan's Syndrome; Bentall Procedure; Flanged Technique; Surgical Treatment

\section{Introduction}

The ascending aorta shows the presence of aneurysmal dilatation growing up to $50 \%$ of its normal diameter. This dilatation may cause significant aortic valve insufficiency even if the aortic valve structure is normal. In addition, a dilated ascending aorta carries the risk of spontaneous dissection and rupture. The size of 


\section{Medical Journal of Clinical Trials \& Case Studies}

this risk depends on the diameter of the aorta and the underlying pathology associated with the aortic wall. Hypertension, congenital bicuspid aorta, Marfan syndrome and atherosclerosis are major risk factors for ascending aortic aneurysm and root expansions $[1,2]$.

In patients with ascending aortic aneurysm, life expectancy has dramatically increased in the last 30 years. The application of the Bentall procedure and its various methods are the most important factors influencing this positive development. Today, various operative techniques for dilated aortic aneurysms are available. A wide spectrum of surgical techniques such as pulmonary autograft, composite root replacement applications and modifications, separate replacement of the lid and the ascending aorta, and valve preserving surgery have been presented [1-4]. In some eligible patients, external wrapping and aortoplasty are offered as alternative treatments [3]. This retrospective study examines the early and midterm outcomes of surgical interventions performed with the same team for patients with ascending aortic aneurysm or additional cardiac problems.

\section{Material and Method}

78 patients underwent operation between Aug 2006 and July 2018 due to ascending aortic aneurysm and/or additional cardiac pathologies in our clinic. Acute or chronic dissecting cases were not included in this retrospective investigation. $54(69,2 \%)$ of the cases were male and $24(30,8 \%)$ were female. Average age was $51.7 \pm$ 9.8 (24-77 years old). The most common cause of ascending aortic aneurysm was annulo-aortic ectasia (58 cases with Marfan's Syndrome, 74,3 \%). Regarding additional cardiac problems, coronary artery disease was present in 12 cases and also, hypertension was present in $69(88,5 \%)$ patients. According to NYHA (New York Heart Association) functional classification, 70 of our patients (89.7\%) were Group I (No physical activity limitation) or II (Slight limitation of physical activity), preoperatively. In the majority of patients, the ejection fractions were between 40 and $60 \%$. Table 1 shows the characteristic information of the patients. Information on aortic dilatation and comorbidities was obtained from preoperative aortic examination and imaging studies. Trans-thoracic echocardiography and contrast-enhanced computerized tomography were performed for all patients (Figures 1A \& 1B). Cardiac catheterization was performed in patients aged more than 50 years (45;
$57.7 \%)$ who had coronary artery disease complaints. Ascending aortic diameter measured in preoperative computed tomography was $6-7 \mathrm{~cm}$ in 42 patients, $7-8 \mathrm{~cm}$ in 26 patients, $8 \mathrm{~cm}$ and more in 10 patients. The diameter of the ascending aorta was $10.2 \mathrm{~cm}$ in the patient with the largest diameter. Figure 2 shows a preoperative ascending aortic aneurysm in one of our cases. There was coronary arterial disease, mitral stenosis, aortic regurgitation, aortic stenosis, and aortic coarctation in $12,3,22,7$ and 2 patients, respectively. The emergency surgical treatment was required in $41(52.5 \%)$ patients.

\begin{tabular}{|c|c|c|}
\hline Parameters & Patients $(n=78)$ & $\%$ \\
\hline Average age & $51,7 \pm 9,8(24-77)$ & \\
\hline \multicolumn{3}{|l|}{ Gender } \\
\hline Men & 54 & 69,2 \\
\hline Women & 24 & 30,8 \\
\hline \multicolumn{3}{|l|}{ NYHA } \\
\hline Class I & 44 & 56,4 \\
\hline Class II & 26 & 33,3 \\
\hline Class III & 5 & 6,5 \\
\hline Class IV & 3 & 3,8 \\
\hline \multicolumn{3}{|l|}{ LV ejection fraction } \\
\hline$>60 \%$ & 62 & 79,5 \\
\hline $40 \%-60 \%$ & 14 & 17,9 \\
\hline $40 \%<$ & 2 & 2,6 \\
\hline \multicolumn{3}{|l|}{ Etiology } \\
\hline Bicuspid aorta & 13 & 16,6 \\
\hline Marfan's Syndrome & 58 & 74,3 \\
\hline Atherosclerosis & 5 & 6,5 \\
\hline Aortic coarctation & 2 & 2,6 \\
\hline \multicolumn{3}{|l|}{ Surgery time } \\
\hline Elective & 37 & 47,5 \\
\hline Emergency & 41 & 52,5 \\
\hline \multicolumn{3}{|l|}{ Accompanying pathologies } \\
\hline Coronary arterial disease & 12 & 15,4 \\
\hline Mitral stenosis & 3 & 3,8 \\
\hline Aortic regurgitation & 9 & 11,5 \\
\hline Aortic stenosis & 7 & 8,9 \\
\hline Aortic coarctation & 2 & 2,6 \\
\hline Peripheral arterial disease & 3 & 3,8 \\
\hline Hypertension & 31 & 39,7 \\
\hline COPD & 9 & 11,5 \\
\hline
\end{tabular}

NYHA: New York Heart Association; COPD: Chronic Obstructive Pulmonary Disease; LV: Left ventricle.

Table 1: Preoperative demographic findings of the patients. 


\section{Medical Journal of Clinical Trials \& Case Studies}

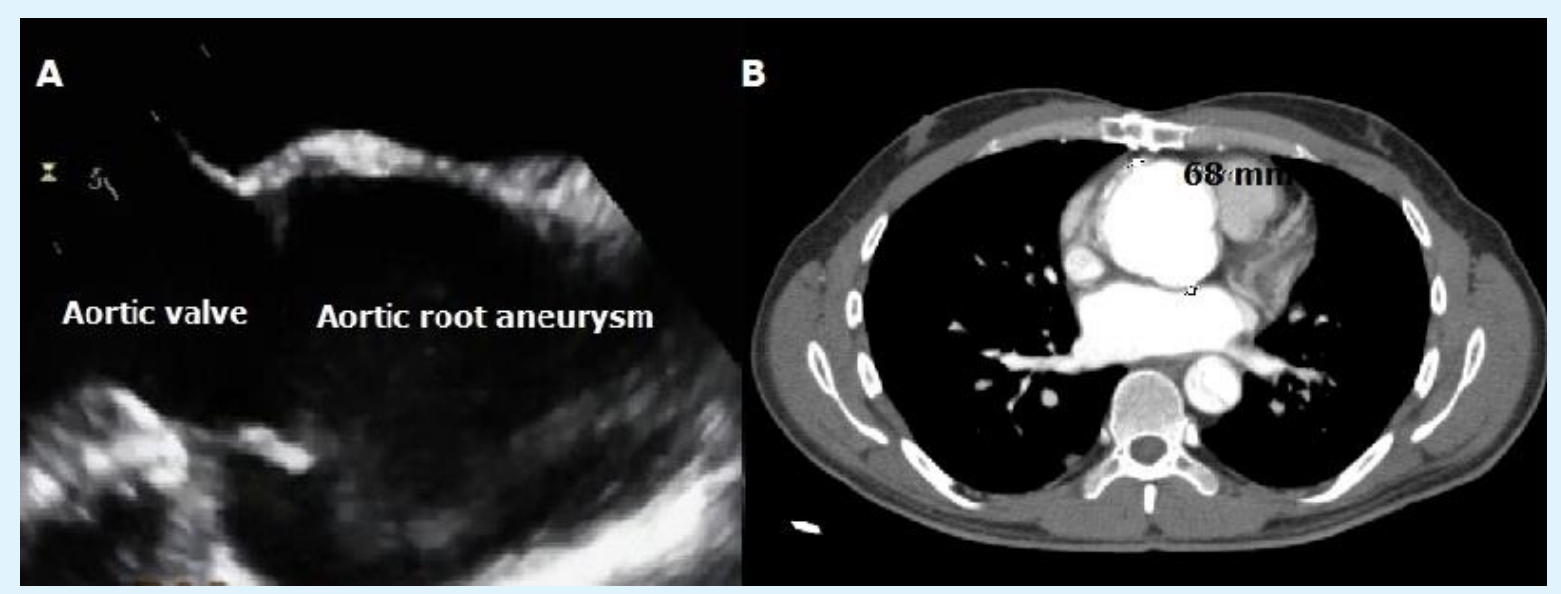

Figure 1: Echocardiographic and computed tomographic images in a patient with ascending aortic aneurysm diagnosed and operated under elective conditions.

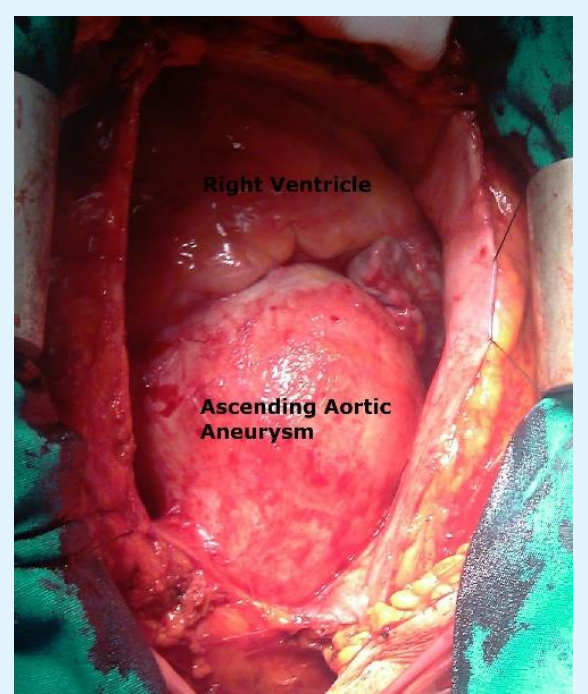

Figure 2: Operative image of a giant ascending aorta (approximately $68 \mathrm{~mm}$ ).

All patients were connected to extracorporeal circulation after median sternotomy. The localized aneurysms that did not extend to the aortic arch were operated with ascending aortic clamping (in 52 patients; $66,6 \%$ ). In these cases, the femoral cannulation was performed and, due to sufficient space on the aorta to place a cross clamp, surgical procedure was completed by clamping the distal ascending aorta. In patients who were not eligible for cross-clamp in ascending aorta, operations were completed using TCA (n=14 patients; $18 \%$ ) or open technique (12 patients; $15,4 \%$ ). In open technique cases, axillary artery cannulation was used as arterial line. The innominate artery was clamped and cerebral perfusion was initiated by decreasing the cardiopulmonary pump flow. TCA was generally used in cases operated before 2010. After 2010 this process was abandoned. Retrograde cerebral perfusion was also performed with deep hypothermia $\left(16^{\circ} \mathrm{C}\right)$ for brain protection in patients who underwent TCA. Decompression was achieved in the majority of cases using right upper pulmonary vein. In all patients, after aortic decompression at the pump, the ascending aorta was separated from the surrounding tissues and released. Myocardial cooling was performed in combination with intermittent ante grade and retrograde cold blood cardioplegia. After the cardiopulmonary bypass in all patients, aortic opening was made by making a longitudinal incision in ascending aorta. First, the sino-tubular junction region and distal portion of the aneurysm were evaluated. Surgical intervention has been determined according to the conditions in these regions. Figure $3 \mathrm{~A}$ shows a case of ascending aortic replacement, and Figure 3B shows an operative image of a patient with coronary arterial bypass surgery in addition to ascending aortic replacement. During operation, proximal and distal anastomoses were reinforced with Teflon strip and supported with various adhesive materials (fibrin glue, cardiac gel). Mechanical bileaflet valves (St Jude, sorin or carbomedics) and dacron tube grafts (Sulzer Vascutek-PA4 9RR, Scodland, Intervascular and Hemashield Gold-Meadox Medical, Inc.) were planted together to form composite grafts. In 


\section{Medical Journal of Clinical Trials \& Case Studies}

patients with Bentall procedure, the coronary arteries were implanted in the graft with the button style (Figure 4). In application of TCA, $15-30 \mu / \mathrm{kg}$ of Fentanyl with propofol and $0.15 \mu / \mathrm{kg}$ of pancuronium were used before the bypass. For cerebral protection, the head is wrapped with ice cushions. Patients with composite graft were started oral anticoagulation (coumadin) after lowmolecular-weight heparin due to mechanical heart valve, and discharged after the desired dose was achieved..

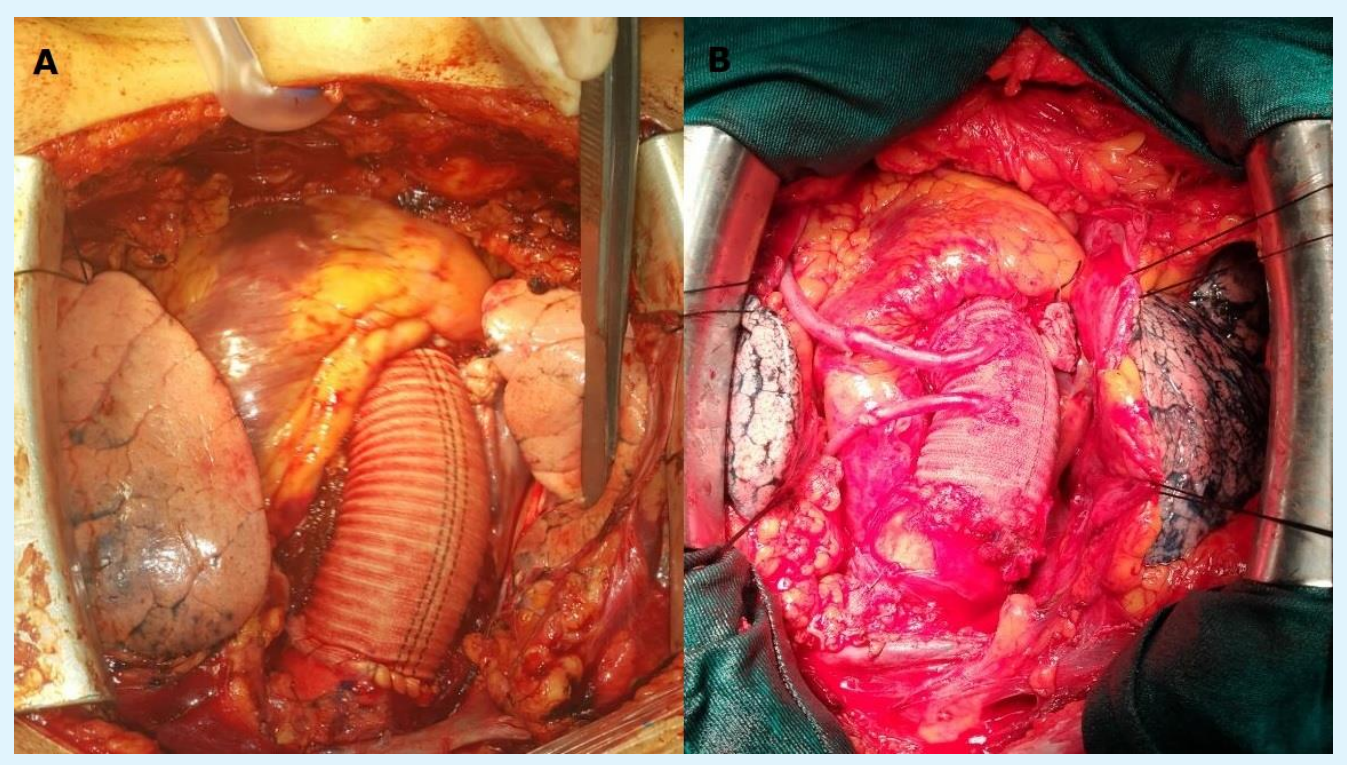

Figure 3A: A case with only an ascending aortic replacement with a prosthetic graft.

Figure 3B: Operation image of the patient who underwent ascending aortic replacement with prosthetic graft and 2vessel coronary bypass surgery.

\section{Results}

Fifty-five $(70.5 \%)$ patients had performed, only, ascending aortic replacement. In addition, 18 of these patients underwent aortic valve resuscitation. Bentall procedure (with additional pathologies and modified) was performed in the 14 patients, aortic valve replacement + ascending aortic graft replacement was made in 9 patients as separate replacement. The operative mortality was occurred in $3(3.8 \%)$ patient with Bentall procedure. These patients were emergency cases and were lost due to low cardiac output. The early postoperative mortality occurred in $1(1.3 \%)$ patient with aortic coarctation. This patient underwent an extraanatomic bypass + ascending aorta replacement (between ascending and descending aorta) for aortic coarctation, and postoperative was lost at 12 hours. The types of operation and postoperative data are shown in Table II. One of the 2 patients who developed renal complications was taken to the hemodialysis program and the other one improved with fluid replacement therapy. In 2 patients with CABG surgery + Bentall procedure, low heart rate syndrome developed and intra-aortic balloon pump (IABP) was applied. Both patients improved following inotropic treatment and IABP. Four patients had postoperative bleeding between 2 and 12 hours, postoperatively. These patients were re-operated. Anastomosis leak was detected in these patients, and bleeding was stopped with repaired sutures. The patients were followed-up in the intensive care unit for a mean of 2.5 days (range 2-6). They were followed-up at the cardiovascular surgery clinic for an average of 7.2 days (range 9-22) and, were discharged. Endocarditis, anticoagulant-related hemorrhage (intracerebral, gastrointestinal, epistaxis, etc.), thromboembolic event and valve thrombosis were not detected. Patients were invited to monthly check-ups in the early period. After 6 months, echocardiographic and tomographic examinations were performed every 3 months, and reoperation was not required in early followup. 


\section{Medical Journal of Clinical Trials \& Case Studies}

\begin{tabular}{|c|c|c|}
\hline Parameters & $\mathbf{n}$ & $\%$ \\
\hline Bentall procedure (Cabrol) & 2 & 2,6 \\
\hline $\begin{array}{l}\text { Modified Bentall procedure with } \\
\text { flanged technique }\end{array}$ & 8 & 10,2 \\
\hline $\begin{array}{l}\text { Supra-coronary ascending aorta } \\
\text { replacement }\end{array}$ & 43 & 55,1 \\
\hline $\begin{array}{l}\text { Supra-coronary ascending aorta } \\
\text { replacement + aortic resuspension }\end{array}$ & 12 & 15,4 \\
\hline $\begin{array}{l}\text { Separate AVR + ascending aorta } \\
\text { replacement }\end{array}$ & 9 & 11,5 \\
\hline $\begin{array}{l}\text { CABG+ modified Bentall procedure } \\
\text { with flanged technique }\end{array}$ & 2 & 2,6 \\
\hline $\begin{array}{l}\text { MVR + modified Bentall procedure } \\
\text { with flanged technique }\end{array}$ & 1 & 1,3 \\
\hline $\begin{array}{l}\text { Modified Bentall procedure with } \\
\text { flanged technique }+ \\
\text { ascending aorta- descending aorta } \\
\text { extra-anatomic graft bypass }\end{array}$ & 1 & 1,3 \\
\hline $\begin{array}{c}\text { CPB with femoral cannulation (cross } \\
\text { clamping) }\end{array}$ & 52 & 66,7 \\
\hline CPB with open technique & 12 & 15,4 \\
\hline CPB with TCA & 14 & 17,9 \\
\hline Average TCA duration (min) & $51(32-80)$ & \\
\hline $\begin{array}{l}\text { Average cardiopulmonary bypass } \\
\text { duration (min) }\end{array}$ & $\begin{array}{l}166(130- \\
202)\end{array}$ & \\
\hline $\begin{array}{l}\text { Average cross clamping duration } \\
\text { (min) }\end{array}$ & $115(85-188)$ & \\
\hline Intra-aortic balloon & 2 & 2,6 \\
\hline Reoperation for bleeding & 4 & 5,2 \\
\hline Renal complications & 2 & 2,6 \\
\hline Neurological complications & 1 & 1,3 \\
\hline \begin{tabular}{|c|} 
Exitus \\
Pperative mortality (low cardiac flow \\
rate)
\end{tabular} & 3 & 3,8 \\
\hline \begin{tabular}{|l|} 
Hospital mortality \\
\end{tabular} & 1 & 1,3 \\
\hline $\begin{array}{l}\text { Intensive care unit staying time } \\
\text { (days) }\end{array}$ & $2,5(2-6)$ & \\
\hline Hospital staying time (days) & $7,2(9-22)$ & \\
\hline \multicolumn{3}{|l|}{ Postoperative NYHA } \\
\hline Class I & 47 & 60,2 \\
\hline Class II & 29 & 37,2 \\
\hline Class III & 1 & 1,3 \\
\hline Class IV & 1 & 1,3 \\
\hline
\end{tabular}

NYHA: New York Heart Association; TCA: Total circulatory arrest; CABG: Coronary artery bypass graft; AVR: Aortic valve replacement; MVR: Mitral valve replacement; CPB: Cardiopulmonary bypass.

Table 2: The operation types and postoperative findings.

\section{Late follow-up}

Seventy-eight patients were followed from 3 months to 3.5 years (mean 2.6 years). Three patients were lost to follow-up because they moved to another city in Turkey. One patient died in a traffic accident and 2 patients lost their malignancy. Three patients could not be reached despite telephone and address records. Approximately $90 \%$ of follow-up patients were in NHYA class I and II. In 10 patients with Marfan syndrome, descending aorta revealed aneurysmatic enlargements. Three of these patients underwent thoracic endovascular aneurysm repair (TEVAR), in others the operation was not indicated and was followed up. Seven patients had aortic valve insufficiency. These patients were followed up by echocardiographic examination every 6 months. Bentall procedure was performed to 3 patients who had previously undergone ascending aortic replacement at the end of the second year. Stent applications were performed in 12 patients due to coronary artery disease at different times.

\section{Discussion}

Today's surgical techniques in ascending aorta aneurysms have brought good early and mid-term results. Surgical success in patients with ascending aortic aneurysms depends on patient profile, age, underlying aortic pathology, extent of distal aorta and sino-tubular junction, experience of the surgeon and the diameter of the aneurysm [1-5]. Ascending aortic resection and ascending aortic replacement is usually performed in patients without dilatation or advanced failure at the level of sino-tubular junction and aortic valve. Surgical interventions such as separate replacement or composite graft replacement are performed in patients with valve insufficiency or junction dilatation. Marfan's Syndrome and other hereditary connective tissue diseases are treated with composite graft replacement in patients with aortic root problems. Bentall procedure and its modifications are usually preferred in such patients. The flanged technique and modified Bentall procedures play an important role in the continuation of the physiological function of the aortic root [5]. The excellent long-term results of the flanged composite graft technique and its low complication rates have been expressed in the most studies [5-7]. These optimistic and successful outcomes lead to excellent morbidity and mortality rates in the long term. In our series, we did not experience any hemodynamic problems in the early and late period in our 


\section{Medical Journal of Clinical Trials \& Case Studies}

patients with flanged technique and the follow-up of these patients is continuing.

The diameter of the ascending aorta is important for surgical timing. Crawford recommends surgical treatment in patients with aortic external diameter of $5 \mathrm{~cm}$ [7]. The Johns Hopkins group shows a $5.5 \mathrm{~cm}$ cut-off value for elective replacement of ascending aorta in patients with Marfan's Syndrome. Svensson, on the other hand, argued that if the diameter of the ascending aorta is 2 times or greater than the normal aortic diameter, surgical intervention should be performed [8,9]. Coady, et al. have determined that the mean diameter at the time of rupture and dissection was $6 \mathrm{~cm}$ [1]. The incidence of rupture or dissection in patients with ascending aortic aneurysm depends on certain parameters such as the quality of the aortic wall, underlying pathology and diameter. A rupture or dissection could be detected in the Marfanoid aortic wall, which is a good example of a weakened aortic wall, even at small distances, especially in those with family history [10]. We preferred to perform elective surgery in 5.5-6 cm diameter and non-dissecting or rupturing ascending aortic patients.

Early clinical reports suggest that best results for aortic root replacement are provided with mechanical valves containing prosthetic conduits and reduce the likelihood of reoperation [11,12]. However, with increasing experience for reoperations and easier bioprosthesis, the use of biological valves has recently increased $[13,14]$. Aortic homografts and recently used pulmonary autografts have been frequently used in patients with ascending aortic aneurysms [14,15]. Since we do not have the possibility of finding and providing homografts and due to lack of economic conditions in our region, we had to use a mechanical valve in cases where a conduit was needed.

Sioris, et al. compared patients with separate aortic valve replacement and Bentall procedure in patients with ascending aortic aneurysms with aortic root dilatation and consequently showed no difference between the two groups during follow-up periods [16]. The clinical profile of the patients who underwent our Bentall procedure was different from their patients. Most of our patients were marfanoid, but there were no patients with Marfan's syndrome in their patients. Due to the excess of Marfan 's syndrome, we could not perform separate replacement in our patients. Besides, Houel et al. noted that Bentall and separate replacement did not affect long-term outcomes. But, they reported that complications of aortic wall were more developed in patients with separate replacement [17].

Karck, et al. compared valve preserving surgery with composite graft replacement in cases with Marfan's Syndrome [18]. They stated that there was no early mortality in patients undergoing the David and Yacoup procedure [19]. The cumulative survival rate was $96 \%$ at 5 years. However, in 3 patients, commissural insufficiency was detected and reoperation was required. Gott, et al. reported that they had undergone valve-sparing surgery and no valve failure developed after 29 years of surgery [20].

Despite the excellent early and long-term outcomes of Bentall, a significant proportion of patients may experience anticoagulant-related complications [21]. Due to this situation, it is of interest to apply biological valve or valve preserving surgery especially in young patients with Marfan's Syndrome. Surgeons, however, seem reluctant of aortic valve preservation due to long-term structural defect-related stabilization problems caused by fibrillin-1 deficiency in patients with Marfan's Syndrome [22]. In general, valve preserving surgery can be performed in patients with ascending aorta and root aneurysm only if the aortic valve structure is normal [23]. We were able to perform valve preserving surgery in 1 patient only by performing aortic valve resuspension in addition to supra-coronary graft anastomosis. Age and age expectancy are also important in patients. Application of wrapping to the aorta can be performed in elderly and high-risk patients. Similarly, treatment with separate replacement can be performed in patients with limited life span [13].

Pathologies such as true or pseudoaneurysms of coronary artery or button anastomoses and early bleeding and kinks affect operative outcomes negatively [24]. To reduce such problems associated with reimplantation of the coronary arteries, the Cabrol procedure was applied, but this procedure was later found to cause more problems than the arterial button technique and was used less frequently [12]. For this reason, it has been shown that the button technique that has been introduced to application gives better results in terms of late complications [25]. We preferred openbutton technique for all of our patients who underwent root replacement. Early reoperation and mortality were not seen in our patients, but we believe that there is a periodic need to follow-up of patients in terms of late complications. In the postoperative period, $\beta$-blockers 


\section{Medical Journal of Clinical Trials \& Case Studies}

have been initiated prophylactically to reduce the progression of aortic dilatation and to prevent aortic complications, especially in patients with Marfan's Syndrome [4]. These patients should be followed up in the early postoperative period and echocardiographically and tomographically for at least 3 years.

In patients with ascending aortic aneurysm, aneurysmal resection and end-to-end anastomosis technique have been used sporadically by some groups. Long-term results have been reported in selected patients as an alternative to graft interposition [2]. However, their long-term durability is controversial. Zher reported that during the last 10 years, 8 patients underwent end-to-end anastomosis surgery and that they had been followed for an average of 11 months and had no problems [26]. With this technique, Vigano, et al. reported that 45 patients had been operated and 1 patient had to undergo reoperation. In living patients, there was little or no re-dilatation and no pseudoaneurysm [27]. Although this technique may be an alternative to aortic interposition grafting, it is not preferred in our patients because there is no possibility of practice in patients with Marfan's Syndrome due to connective tissue pathology.

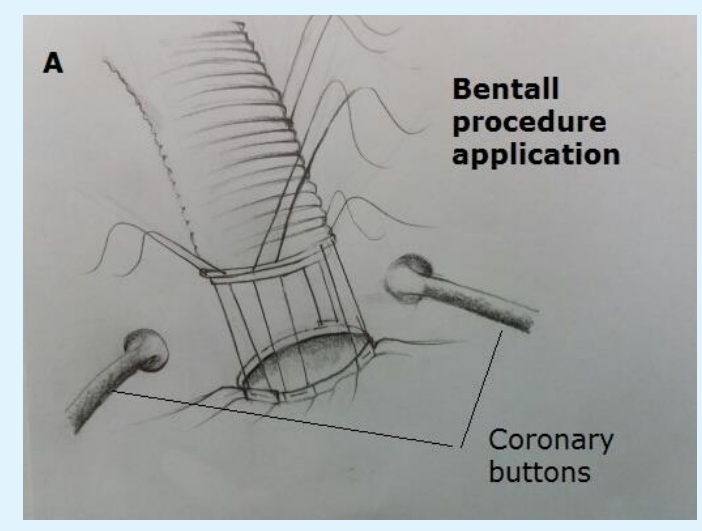

Figure 4: Schematic drawing showing ascending aortic + root replacement with Bentall procedure.

\section{Conclusion}

In conclusion, patients with ascending aortic aneurysms should be closely monitored for the timing of surgery due to the risk of dissection and rupture, and patients with operation indications should undergo surgery without delay. Although various surgical interventions can be applied according to the aortic valve status, especially in patients with Marfan's Syndrome, root replacement with composite graft, and Bentall modifications and button anastomosis of coronaries in composite graft applications should be the preferred surgical procedure.

\section{References}

1. Coady MA, Rizzo JA, Hammond GL (1997) What is the appropriate size criterion for resection of thoracic aortic aneurysms?. J Thorac Cardiovasc Surg 113: 476-491.

2. Bentall HH, De Bono A (1968) A technique for complete replacement of the ascending aorta. Thorax 23(4): 338-339.

3. Massetti M, Veron S, Neri E, Coffin O, le Page O, et al. (2004) Long-term durability of resection and end-toend anastomosis for ascending aortic aneurysms. J Thorac Cardiovascu Surgery 127(5): 1381-1387.

4. Burgstaller JM, Held U, Mosbahi S, Stak D, Steurer J, et al. (2018) A systemic review and meta-analysis: longterm results of the Bentall versus the David procedure in patients with Marfan syndrome. Eur J Cardiothorac Surg 54(3): 411-419.

5. Yakut C (2001) A new modified Bentall procedure: the flanged technique. Ann Thorac Surg 71(6): 20502052.

6. Kirali K, Mansuroglu D, Omeroglu SN, Erentuğ V, Mataraci I, et al. (2002) Fiveyear experience in aortic root replacement with the flanged composite graft. Ann Thorac Surg 73(4): 1130-1137.

7. Crawford ES, Coselli JS, Svensson LG, Safi HJ, Hess KR (1990) Diffuse aneurysmal disease (chronic aortic dissection, Marfan, and mega aorta syndromes) and multiple aneurysm. Treatment by subtotal and total aortic replacement emphasizing the elephant trunk operation. Ann Surg 211(5): 521-537.

8. Gott VL, Pyeritz RE, Magovern GJ, Cameron DE, McKusick VA (1986) Surgical treatment of aneurysms of the ascending aorta in the Marfan Syndrome. New Engl J Med 314: 1070-1074.

9. Svensson LG, Crawford ES, Coselli JS, Safi HJ, Hess KR (1989) Impact of cardiovascular operation on 


\section{Medical Journal of Clinical Trials \& Case Studies}

survival in the Marfan patient. Circulation 80 (3 Pt 1): 1233-1242.

10. Pyeritz RE (1993) Marfan syndrome: current and future clinical and genetic management of cardiovascular manifestations. Sem Thorac Cardiovasc Surg 5(1): 11-69.

11. Peterss S, Charilaou P, Dumfarth J, Li Y, Bhandari R, et al. (2016) Aortic valve disease with ascending aortic aneurysm: Impact of concomitant root-sparing (supracoronary) aortic replacement in nonsyndromic patients. J Thorac Cardiovasc Surg 152: 791-798.

12. Cabrol C, Pavie A, Gandjbakhch I, Villemot JP, Guiraudon G, et al. (1981) Complete replacement of the ascending aorta with reimplantation of the coronary arteries: new surgical approach. J Thorac Cardiovasc Surg 81(2): 309-315.

13. Yun KL, Miller DC, Fann JI, Mitchell RS, Robbins RC, et al. (1997) Composite valve graft versus separate aortic valve and ascending aortic replacement. Is there still a role for separate procedure? Circulation 96(9): II-368-375.

14. Elkins RC, Lane MM, McCue C (1999) Ross procedure for ascending aortic replacement. Ann Thorac Surg 67(6): 1843-1845.

15. David TE, Omran A, Ivanov J, Armstrong S, de Sa MP, et al. (2000) Dilation of the pulmonary autograft after the Ross procedure. J Thorac Cardiovasc Surg 119(2): 210-220.

16. Sioris T, David TE, Ivanov J, Armstrong S, Feindel CM (2004) Clinical outcomes after separate and composite replacement of the aortic valve and ascending aorta. J Thorac Cardiovasc Surg 128(2): 260-265.

17. Houel R, Soustelle C, Kirsch M, Hillion ML, Renaut C, et al. (2002) Long-term results of the Bentalll operation versus separate replacement of the ascending aorta and aortic valve. J Heart Valve Dis 11(4): 485-491.

18. Karck M, Kallenbach K, Hagl C, Rhein C, Leyh R, et al. (2004) Aortic root surgery in Marfan syndrome: Comparison of aortic valve-sparing reimplantation versus composite grafting. J Thorac Cardiovasc Surg 127(2): 391-398.
19. Tambeur L, David TE, Unger M, Armstrong S, Ivanov J, et al. (2000) Results of surgery for aortic root aneurysm in patients with the Marfan's Syndrome. Eur J Cardiothorac Surg 17(4): 415-419.

20. Gott VL, Greene S, Alejo DE, Cameron DE, Naftel DC, et al. (1999) Replacement of the aortic root in patients with Marfan's syndrome. N Engl J Med 340(17): 13071313.

21. Nicolo F, Romeo F, Lio A, Bovio E, Scafuri A, et al. (2017) Long-Term Results of Aortic Root Surgery in Marfan Syndrome Patients: A Single-Center Experience. J Heart Valve Dis 26: 397-404.

22. Fleisher KJ, Nousari HC, Anhalt GJ, Stone CD, Laschinger JC (1997) Immunohistochemical abnormalities of fibrillin in cardiovascular tissue in Marfan's syndrome. Ann Thorac Surg 63(4): 10121017.

23. David TE, Armstrong S, Ivanov J, Webb GD (1999) Aortic Valve Sparing Operations: An Update. Ann Thorac Surg 67(6): 1840-1842.

24. Meijboom LJ, Nollen GJ, Merchant N, Webb GD, Groenink M, et al. (2002) Frequency of coronary ostial aneurysms after aortic root surgery in patients with the Marfan syndrome. Am J Cardiol 89(9): 11351138.

25. Pokela R, Juvonen T, Sata J, Karkola $P$ (1998) Composite graft replacement for treatment of ascending aortic aneurysms using original Bentall-De Bono procedure or its open button modification. Eur J Cardio-thorac Surg 13(4): 484-485.

26. Zehr KJ, Sternik L, Schaff HV (2000) Resection and primary end-to-end anastomosis of ascending aortic aneurysms. Circulation 102: 11400-11401.

27. Vigano M, Rinaldi M, D'Armini AM, Boffini M, Zattera GF, et al. (2002) Ascending aortic aneurysms treated by cuneiform resection and end-to-end anastomosis through a ministernotomy. Ann Thorac Surg 74(5): S1789-S1791. 